\title{
Body Weight Gain Date Time of Reference Timepoint
}

National Cancer Institute

\section{Source}

National Cancer Institute. Body Weight Gain Date Time of Reference Timepoint. NCI

Thesaurus. Code C119771.

The date and time of a specific reference point for the body weight gain assessment. 